\title{
Relation of the degree of obesity in childhood to adipose tissue insulin resistance
}

\author{
Emilia Hagman ${ }^{1,2}(0)$ Omri Besor ${ }^{3} \cdot$ Karen Hershkop $^{1} \cdot$ Nicola Santoro $^{4} \cdot$ Bridget Pierpont $^{4} \cdot$ Mariana Mata $^{4}$. \\ Sonia Caprio ${ }^{4} \cdot$ Ram Weiss ${ }^{3}$
}

Received: 5 November 2018 / Accepted: 29 December 2018 / Published online: 12 January 2019

(c) The Author(s) 2019

\begin{abstract}
Aims In this study, we investigated whether adipose tissue insulin resistance (IR) is affected by the degree of obesity during the fasting and post-prandial state, independent of glucose tolerance among obese children and adolescents. We also tested whether systemic subclinical inflammation is associated with adipose tissue IR.

Methods Subjects were recruited to the Yale Pathophysiology of Type 2 Diabetes in Youth Study (NCT01967849). An oral glucose-tolerance test was performed to establish glucose-tolerance status and blood samples were drawn for measurement of free fatty acids (FFAs), to calculate the area under the curve (AUC) of FFA. Adipose tissue insulin resistance was calculated as the product of insulin and FFA concentrations.

Results In total, 671 children and adolescents (58.6\% females) were included with a mean age of 13.3(2.7) years and BMI $Z$ score of 2.45(0.31). The degree of obesity emerged as an independent predictor of both fasting and post-prandial adipose IR, $p<0.0001$. Higher degree of obesity was associated with greater AUC FFA (lower suppression) compared to lower degree of obesity, $p=0.01$. Furthermore, higher levels of IL- 6 were positively associated with post-prandial adipose tissue IR, $p=0.02$. Conclusions The degree of obesity in childhood and adolescence is strongly associated with adipose tissue IR independent of glucose tolerance. This is reflected not only in calculated indices of adipose IR but also in lower suppression of FFAs during the OGTT regardless of glucose tolerance or fasting adipose tissue IR. Furthermore, markers of subclinical inflammation such as IL-6 are associated with adipose tissue IR, independent of other factors.
\end{abstract}

Keywords Pediatric obesity $\cdot$ Insulin resistance $\cdot$ Fatty acid $\cdot$ Adipose tissue

\section{Introduction}

Managed by Antonio Secchi.

Electronic supplementary material The online version of this article (https://doi.org/10.1007/s00592-018-01285-3) contains supplementary material, which is available to authorized users.

Emilia Hagman

emilia.hagman@ki.se

1 Department of Human Metabolism and Nutrition, Braun School of Public Health, Hebrew University, Jerusalem, Israel

2 Department of Clinical Science, Intervention and Technology, Karolinska Institutet, Blickagången 6A, 14157 Stockholm, Sweden

3 Department of Pediatrics, Ruth Rappaport Children's Hospital, Rambam Medical Center, Haifa, Israel

4 Department of Pediatrics, Yale University, New Haven, CT, USA
Insulin resistance is a reduction in the response to insulin of specific tissues and results in reduced inhibition of lipolysis in adipose tissue, which, in turn, contributes to a reduced skeletal muscle glucose uptake and an increased hepatic glucose production [1]. We have previously shown that, in children with obesity, the presence of an adverse metabolic phenotype is independently affected by both the degree of obesity and by a reduction of whole-body insulin sensitivity [2]. Adipose tissue is an endocrine organ that affects both glucose and lipid metabolism by releasing adipokines, pro-inflammatory factors, and free fatty acids (FFAs), all of which affect glucose metabolism and alter insulin signaling [3]. Altered glucose tolerance in children and adolescents with obesity is associated with greater resistance to insulin in adipose tissue [4], yet the relation of adipose insulin 
sensitivity, independent of whole-body insulin sensitivity, and the degree of obesity in the pediatric age group are less clear.

Indices describing the sensitivity of adipose tissue to insulin have been developed using fasting as well as postprandial insulin and free fatty acid concentrations [5]. Adipose tissue release of FFA via unsuppressed lipolysis is the main manifestation of tissue insulin resistance (IR). Circulating FFAs play a major role in the development of reduced insulin sensitivity [6,7] and beta-cell dysfunction [8], both via lipotoxicity. It is, thus, crucial to evaluate the sensitivity of adipose tissue to insulin specifically in the prandial state to study the delicate interplay of circulating FFAs with insulin secretion and action. While fasting indices of adipose insulin resistance have been studied in obese children $[4,9$, 10], little is known about the prandial state, specifically in this context of obesity-related insulin resistance. Infiltration of adipose tissue by macrophages is probably one of the drivers of adipose IR playing a critical role in the establishment of the chronic inflammatory state and metabolic dysfunction [11], which are commonly detected in children with obesity and may be exacerbate during the developmental stage of puberty $[12,13]$.

It has recently been shown that adipose tissue IR in children and adolescents [4] as well as adults [5], defined as reduced suppression of FFAs during the oral glucosetolerance test (OGTT), is associated with prediabetes and diabetes and with an altered adipocytokine profile. Moreover, it has been shown that obese compared to non-obese children and adolescents has reduced insulin sensitivity of adipose tissue [9], particularly in the fasting state. In the current analysis, we expanded this fundamental observation and performed additional analyses to investigate if, among obese children and adolescents, adipose tissue IR is affected by the degree of obesity during the fasting and post-prandial state, independent of glucose tolerance. We also investigate whether systemic subclinical inflammation, reflected by C-reactive protein (CRP) and interleukin-6 (IL6) concentrations, is associated with adipose tissue IR. In other words, we attempted to link obesity per-se and subclinical inflammation with fasting and post-prandial adipose IR while removing the effect of glucose tolerance, a factor that has previously been shown to confound these relations.

\section{Methods}

\section{Subjects}

Subjects were recruited to the Yale Pathophysiology of Type 2 Diabetes in Youth Study, a long-term, multiethnic cohort aimed at studying the early alternations in glucose metabolism in obese children and adolescents (NCT01967849).
Subjects were eligible to participate if they were at the age of 7-20 years and had a body mass index (BMI) that exceeded the 95th centile for age and sex [14]. Following subject assent and parental consent, a complete medical history and physical examination were performed. Weight was measured using a scale (Tanita Corp), and height was measured in triplicate with a wall-mounted stadiometer. Obesity categories according to age and sex-specific BMI percentiles were defined as: class I obesity ( $\geq 95$ th percentile to $<120 \%$ of the 95th percentile), class II obesity $(\geq 120-<140 \%$ of the 95 th percentile), class III obesity $(\geq 140-<160 \%$ of the 95th percentile), and class IV obesity ( $\geq 160 \%$ of the 95 th percentile) [12].

An oral glucose-tolerance test (OGTT, $1.75 \mathrm{~g} / \mathrm{kg}$ body weight up to $75 \mathrm{~g}$ ) was performed to establish glucose-tolerance status. Subjects were studied at the Yale Pediatric Clinical Center at 08:00 am after a 10-h overnight fast as previously reported [15]. Ranges of 2-h glucose were categorized into four groups: $1: \leq 100 \mathrm{mg} / \mathrm{dl}, 2: 101-120 \mathrm{mg} /$ $\mathrm{dl}, 3: 121-140 \mathrm{mg} / \mathrm{dl}$, and $4>140 \mathrm{mg} / \mathrm{dl}$ at $2 \mathrm{~h}$ following glucose ingestion.

Blood samples were drawn for the measurement of free fatty acids (FFAs) at 0, 30, 60, and $120 \mathrm{~min}$. All blood samples were immediately put on ice, centrifuged for $30 \mathrm{~min}$, and stored at $-80^{\circ} \mathrm{C}$. FFAs samples were allowed to clot first, and then, serum was separated per the instructions of the assay manufacturer. All subjects tested negative for autoimmune markers for type 1 diabetes (insulin antibody, GAD65, and islet cell antibody 512). The study was ethically approved by the Human Investigations Committee of the Yale School of Medicine.

\section{Analytical methods}

Plasma glucose was determined using YSI 2700 Analyzer (Yellow Springs Instruments). Plasma insulin and total adiponectin levels were measured using double antibody RIAs (Millipore inc. insulin intra- and interassay coefficients of variation are 6.8 and $11.6 \%$, respectively; adiponectin intraand interassay coefficients of variation are 7.1 and $9.5 \%$, respectively). C-reactive protein (CRP) was measured using the ultrasensitive assay (Kamiya Biomedical). For CRP, the intra-assay coefficient of variation is no greater than $3.0 \%$, and the interassay coefficient of variation is no greater than $11.6 \%$. IL-6 was measured using a highly sensitive solidphase ELISA (R\&D Systems) (lower limit of detection: $0.16 \mathrm{pg} / \mathrm{ml}$; intra- and interassay coefficients of variation: 7.4 and $7.8 \%$, respectively). Plasma FFAs were determined using an enzymatic colorimetric method assay for the quantitative determination of non-esterified fatty acids in serum (Wakochem, Ind.). Plasma leptin levels were measured using an RIA assay from Linco (leptin intra- and interassay coefficients of variation: 6.5 and $8.0 \%$, respectively). 


\section{Calculations}

Insulin sensitivity was calculated using the OGTT-derived whole-body insulin sensitivity index (WBISI, also known as the Matsuda index) [16]. WBISI is based on the values of insulin (microunits/ml) and glucose $(\mathrm{mg} / \mathrm{dl}$ ) obtained throughout the OGTT and the corresponding fasting values [16]. The fasting adipose insulin resistance (Adipo-IR) was calculated as the product of fasting insulin and FFA concentrations [17]. An additional index of adipose insulin resistance in the prandial state was calculated using the mean of the product of fasting insulin and FFA concentrations at time $0,30,60$, and $120 \mathrm{~min}$ at the OGTT [5]. Area under the curve (AUC) of FFAs during the OGTT, as means to express FFA suppression during the study, was calculated using the trapezoidal rule.

\section{Statistical analysis}

Data are presented as means \pm standard deviations. The primary outcome of the analysis was the prandial adipose tissue insulin resistance index. The variables Adipo-IR, WBISI, CRP, and IL-6 values were log-transformed using the natural logarithm before analysis. Crude analyses were performed using the analysis of variance or the Chi-square test where appropriate. In adjusted analyses for the primary and secondary aims, linear regression models were applied.
Independent variables in these models included sex, age, race, $2 \mathrm{~h}$ glucose category, and degree of obesity category. Sensitivity analyses were performed including only NGT subjects. The analysis was performed using the SAS Statistical software (version 9.4, SAS Institute Inc, Cary, NC, USA).

\section{Results}

\section{Study participants (Table 1)}

In total, 671 children and adolescents participated in the analysis with a mean age of $13.3(2.7)$ years. The majority of participants were females $(58.6 \%)$ and the race distribution was $47.8 \%$ Caucasian, $32.5 \%$ African-American, and $19.7 \%$ Hispanic. The BMI $Z$ score was $2.45(0.31)$ and ranged between 1.65 and 3.50. The distribution of participants within the degree of obesity categories was $18.3 \%$, $36.7 \%, 25.9 \%$, and $19.1 \%$ in obesity categories $1,2,3$, and 4 , respectively. Of note, the rate of Caucasians decreased, while the rate of African-Americans and Hispanics increased with greater degrees of obesity.

Both indices of adipose tissue IR (fasting and prandial) increased with the degree of obesity $(p<0.0001)$, while whole-body insulin sensitivity (WBISI) decreased with

Table 1 Study participants by obesity categories

\begin{tabular}{|c|c|c|c|c|c|}
\hline & Obesity class I, $n=123(18.3 \%)$ & $\begin{array}{l}\text { Obesity class II, } \\
n=246(36.7 \%)\end{array}$ & $\begin{array}{l}\text { Obesity class III, } \\
n=174(25.9 \%)\end{array}$ & $\begin{array}{l}\text { Obesity class VI, } \\
n=128(19.1 \%)\end{array}$ & $\chi^{2} / \mathrm{ANOVA}$ \\
\hline Females (\%) & 64.4 & 60.2 & 58.6 & 50.0 & 0.12 \\
\hline $\begin{array}{l}\text { Caucasian/African-American/ } \\
\text { Hispanic }\end{array}$ & $65.0 / 17.1 / 17.9$ & $50.0 / 33.3 / 16.7$ & $43.1 / 34.5 / 22.4$ & $33.6 / 43.0 / 23.4$ & $<0.0001$ \\
\hline Age (years) & $13.5 \pm 2.7$ & $13.5 \pm 2.7$ & $13.2 \pm 2.7$ & $13.1 \pm 2.9$ & 0.40 \\
\hline BMI $Z$ score & $1.98 \pm 0.15$ & $2.36 \pm 0.13$ & $2.61 \pm 0.11$ & $2.85 \pm 0.17$ & $<0.0001$ \\
\hline Fasting glucose (mg/dl) & $91.0 \pm 7.4$ & $92.3 \pm 9.5$ & $92.8 \pm 7.6$ & $94.3 \pm 9.6$ & 0.02 \\
\hline $2 \mathrm{~h}$ glucose $(\mathrm{mg} / \mathrm{dl})$ & $120.6 \pm 23.5$ & $121.7 \pm 28.4$ & $119.7 \pm 25.1$ & $126.9 \pm 30.7$ & 0.12 \\
\hline $2 \mathrm{~h}$ glucose category ${ }^{\mathrm{a}}$ & $17.1 / 38.2 / 30.9 / 13.8$ & $17.9 / 37.0 / 26.0 / 19.1$ & $21.3 / 35.1 / 27.0 / 16.7$ & $12.5 / 35.2 / 31.2 / 21.1$ & 0.64 \\
\hline $\begin{array}{l}\text { Fasting Adipo-IR }(\mathrm{mmol} / \mathrm{l} \times \\
\mu \mathrm{U} / \mathrm{ml})\end{array}$ & $14.7 \pm 8.7$ & $17.4 \pm 11.8$ & $20.6 \pm 10.9$ & $25.8 \pm 17.0$ & $<0.0001$ \\
\hline $\begin{array}{l}\text { Prandial Adipo-IR }(\mathrm{mmol} / \mathrm{l} \times \\
\mu \mathrm{U} / \mathrm{ml})\end{array}$ & $31.6 \pm 27.1$ & $35.5 \pm 30.1$ & $39.5 \pm 24.3$ & $49.5 \pm 41.4$ & $<0.0001$ \\
\hline WBISI & $2.16 \pm 1.35$ & $1.80 \pm 0.98$ & $1.56 \pm 0.85$ & $1.53 \pm 0.88$ & $<0.0001$ \\
\hline CRP (mg/l) & $1.85 \pm 3.79$ & $2.75 \pm 3.91$ & $4.01 \pm 5.87$ & $6.44 \pm 6.44$ & $<0.0001$ \\
\hline IL-6 (pg/ml) & $2.07 \pm 2.95$ & $2.26 \pm 1.69$ & $2.56 \pm 1.93$ & $4.24 \pm 3.18$ & $<0.0001$ \\
\hline Leptin (ng/ml) & $19.9 \pm 9.8$ & $28.6 \pm 11.6$ & $34.6 \pm 13.8$ & $43.5 \pm 15.4$ & $<0.0001$ \\
\hline Adiponectin $(\mu \mathrm{g} / \mathrm{ml})$ & $7.8 \pm 4.0$ & $7.9 \pm 4.1$ & $7.3 \pm 3.4$ & $7.5 \pm 3.9$ & 0.45 \\
\hline
\end{tabular}

Obesity class I represents $100-120 \%$, class II: $120-140 \%$, class III: $140-160 \%$, and class IV $\geq 160 \%$ of the 95 th percentile

$B M I$ body mass index, WBISI whole-body insulin sensitivity index

${ }^{a} 2 \mathrm{~h}$ glucose categories correspond to $1: \leq 100 \mathrm{mg} / \mathrm{dl}, 2: 101-120 \mathrm{mg} / \mathrm{dl}, 3: 121-140 \mathrm{mg} / \mathrm{dl}, 4>140 \mathrm{mg} / \mathrm{dl}$ at $2 \mathrm{~h}$ after glucose ingestion on the OGTT 
degree of obesity $(p<0.0001)$. No differences in $2 \mathrm{~h}$ glucose between obesity categories were detected $(p=0.64)$.

\section{Predictors of adipose tissue insulin resistance (Table 2)}

We identified the predictors of adipose tissue IR using linear regression models where the adipose IR index was used as the dependent variable, and sex, age, race, 2 h glucose category, and the degree of obesity were used as independent variables. In these models, the degree of obesity (as reflected by obesity categories) emerged as an independent significant predictor of both indices of adipose insulin resistance (ln fasting and prandial Adipo-IR). Specifically, rising degrees of obesity were associated with greater fasting and prandial adipose IR as well as with lower whole-body insulin sensitivity (Fig. 1). Of note, in agreement with the previous findings, glucose tolerance, assessed using the $2 \mathrm{~h}$ glucose category even within the normal range, was also an independent significant predictor of Adipo-IR.

Limiting the analysis to subjects with NGT (to examine these findings regardless of alterations in glucose metabolism known to affect the outcomes) only mildly attenuated these results and the degree of obesity remained a significant predictor of adipose insulin resistance in the models.

Limiting the analysis to subjects with data on leptin $(n=658)$ and adiponectin $(n=662)$ revealed in adjusted
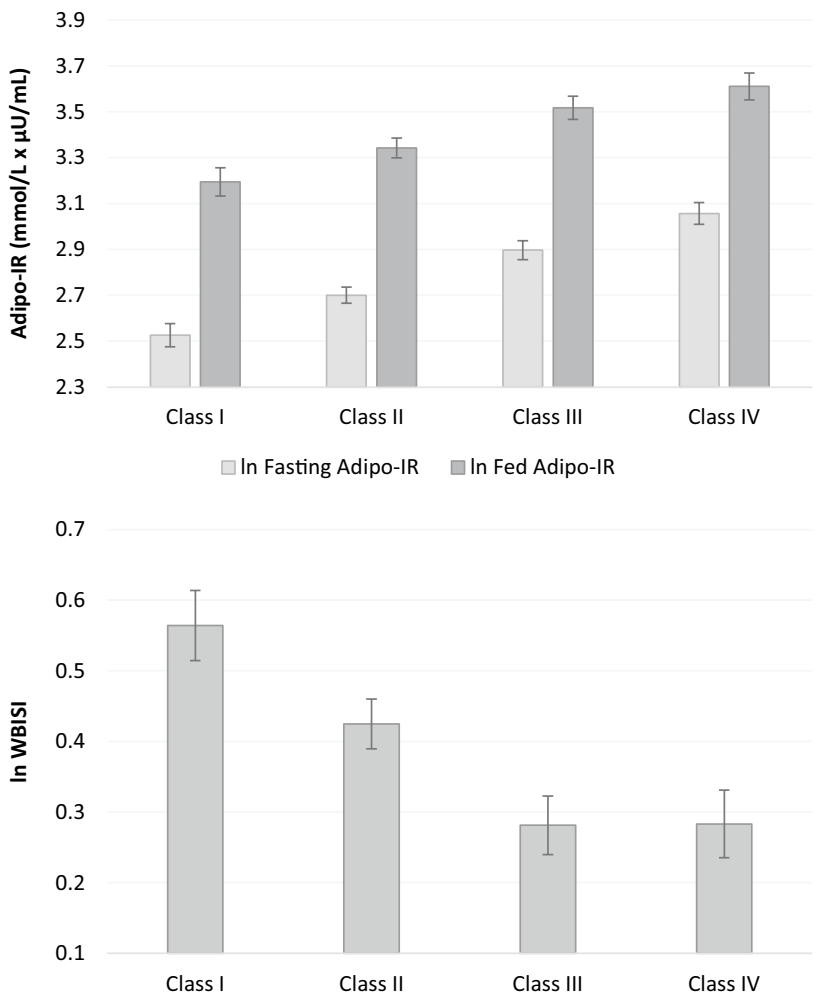

Fig. 1 Adipose insulin resistance and whole-body insulin sensitivity across obesity categories adjusted for sex, age, race, and $2 \mathrm{~h}$ glucose category. Data are presented as adjusted means and SE. $p$ for trend are $<0.0001$ in all the analyses
Table 2 Linear regression models for predictors for adipose tissue insulin resistance (AT-IR) and WBISI

\begin{tabular}{|c|c|c|c|c|c|c|}
\hline & \multicolumn{2}{|c|}{ ln fasting AT-IR } & \multicolumn{2}{|c|}{ ln prandial AT-IR } & \multicolumn{2}{|l|}{$\ln$ WBISI } \\
\hline & Estimate & $p$ & Estimate & $p$ & Estimate & $p$ \\
\hline Sex (male vs. female) & -0.06 & 0.16 & 0.07 & 0.16 & 0.05 & 0.23 \\
\hline Age & -0.01 & 0.29 & 0.01 & 0.20 & -0.01 & 0.44 \\
\hline Race (AA vs. Caucasians) & 0.02 & 0.75 & 0.11 & 0.07 & -0.04 & 0.43 \\
\hline Race (Hispanic vs. Caucasians) & 0.03 & 0.57 & 0.02 & 0.81 & -0.10 & 0.08 \\
\hline $2 \mathrm{~h}$ glucose category & 0.19 & $<0.0001$ & 0.21 & $<0.0001$ & -0.28 & $<0.0001$ \\
\hline Obesity class II vs. class I & 0.17 & 0.003 & 0.15 & 0.042 & -0.14 & 0.018 \\
\hline Obesity class III vs. class I & 0.37 & $<0.0001$ & 0.32 & $<0.0001$ & -0.28 & $<0.0001$ \\
\hline Obesity class IV vs. class I & 0.53 & $<0.0001$ & 0.42 & $<0.0001$ & -0.28 & $<0.0001$ \\
\hline \multicolumn{7}{|c|}{ Estimates for adipose tissue insulin resistance and WBISI in NGT subjects $(n=551)$} \\
\hline Sex (male vs. female) & -0.05 & 0.24 & 0.06 & 0.27 & 0.06 & 0.17 \\
\hline Age & -0.003 & 0.73 & 0.02 & 0.025 & -0.01 & 0.06 \\
\hline Race (AA vs. Caucasians) & 0.02 & 0.66 & 0.13 & 0.042 & -0.04 & 0.41 \\
\hline Race (Hispanic vs. Caucasians) & 0.08 & 0.18 & 0.06 & 0.43 & -0.15 & 0.0130 \\
\hline $2 \mathrm{~h}$ glucose category & 0.16 & $<0.0001$ & 0.20 & $<0.0001$ & -0.24 & $<0.0001$ \\
\hline Obesity class II vs. class I & 0.13 & 0.036 & 0.13 & 0.10 & -0.07 & 0.24 \\
\hline Obesity class III vs. class I & 0.34 & $<0.0001$ & 0.32 & 0.0002 & -0.25 & 0.0001 \\
\hline Obesity class IV vs. class I & 0.50 & $<0.0001$ & 0.45 & $<0.0001$ & -0.25 & 0.0007 \\
\hline
\end{tabular}

Categories for $2 \mathrm{~h}$ glucose represent $\leq 100 \mathrm{mg} / \mathrm{dl}, 101-120 \mathrm{mg} / \mathrm{dl}, 121-140 \mathrm{mg} / \mathrm{dl}$, and $>140 \mathrm{mg} / \mathrm{dl}$

Obesity class I represents $100-120 \%$, class II: $120-140 \%$, class III: $140-160 \%$, and class IV $\geq 160 \%$ of the 95th percentile

WBISI whole-body insulin sensitivity index, $A A$ African-American 
models that higher levels of adiponectin were significantly associated with lower fasting Adipo-IR $(\beta=-0.03$, $p<0.0001)$ and post-prandial Adipo-IR $(\beta=-0.04$, $p<0.0001$ ), while the degree of obesity remained a significant predictor of adipose insulin resistance in both models. Leptin was not independently associated with Adipo-IR indices (data not shown).

\section{Relation of the post-prandial FFA profile and the degree of obesity}

Fasting FFAs increased across obesity categories ( $p$ for trend $=0.0007$ ). However, only in subjects with class IV obesity, fasting FFAs were significantly greater than the other obesity categories ( $p=0.03$, Fig. 2$)$. After adjustment for baseline FFA, no differences in post-prandial FFA were observed between obesity categories $(p=0.22)$. Of note, boys had $0.015 \mathrm{mmol} / \mathrm{l}$ higher fasting FFA levels than girls. $(p=0.02)$. There were no statistical significant differences in other fasting or $120^{\prime}$ glucose or FFA levels between the sexes within each obesity category (data not shown). Levels of glucose, insulin, and free fatty acids (FFA) during oral glucose-tolerance test divided by obesity class I-IV are provided in Supplementary Fig. 1.

The suppression of FFAs during the OGTT was expressed as AUC of FFAs, where greater values represent lower suppression. We compared the AUC of FFA during the OGTT between obesity categories while adjusting for sex, age, race, $2 \mathrm{~h}$ glucose category, and fasting adipose tissue IR. Obesity class IV had a higher AUC FFA (lower suppression) compared to class I ( $p=0.01$, Fig. 3 ). The FFA AUC was also higher in boys, increased with fasting Adipo-IR, and with age within the full sample. Upon limiting the analysis to those with NGT, obesity class IV still had higher AUC FFA than obesity class I.

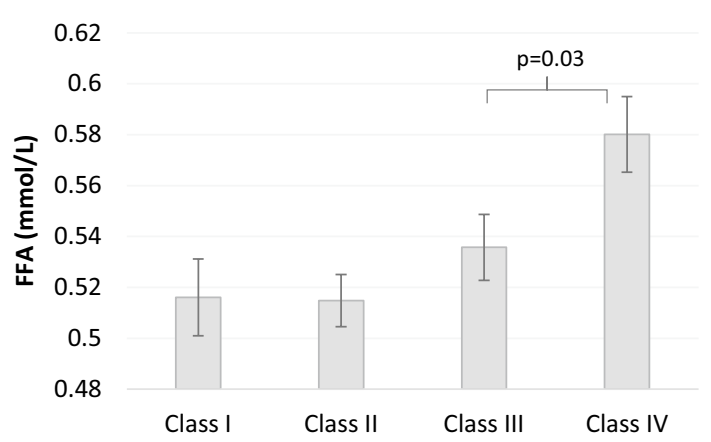

Fig. 2 Levels of fasting free fatty acids by obesity category, $p$ for trend $=0.0007$

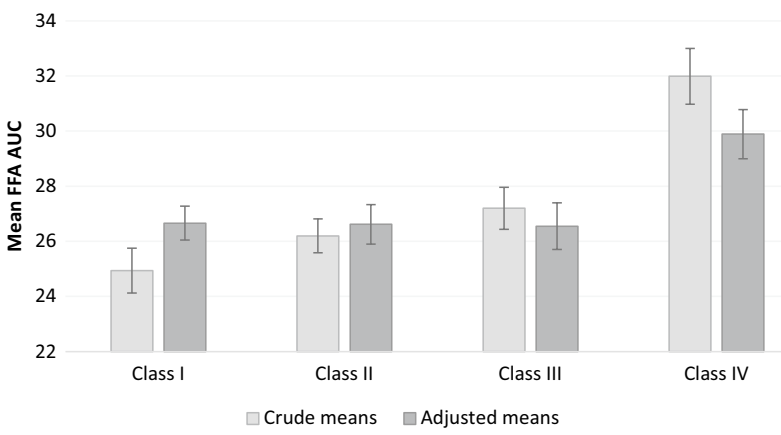

Fig. 3 Crude and adjusted means (SE) for the area under the curve of free fatty acids (FFA) during 2-h oral glucose-tolerance test by obesity categories. Higher values represent lower suppression of FFAs. $p$ for trend for crude and adjusted means are $<0.001$ and 0.0149 respectively

\section{Relation of adipose tissue insulin resistance and markers of inflammation}

To test the relation of inflammatory markers and adipose tissue insulin resistance, we first tested simple correlations of adipose insulin resistance indices and IL-6/CRP. Later, we incorporated IL-6 and CRP separately into the models described earlier where indices of adipose IR were the dependent variables.

In crude analyses, both $(\ln ) \mathrm{CRP}$ and $(\ln ) \mathrm{IL}-6$ were positively associated with (ln)fasting Adipo-IR ( $p=0.003$ and 0.0001 , respectively) and with (In) fed Adipo-IR ( $p=0.01$ and 0.0004 respectively). (ln)WBISI was not associated with $(\ln ) \mathrm{CRP}(p=0.08)$ or $(\ln ) \mathrm{IL}-6(p=0.06)$.

Investigating the effect of CRP and IL-6 on adipose IR indices after adjusting for the same covariates as in the models presented in Table 2, revealed that higher levels of IL-6 were positively associated with (ln) post-prandial Adipo-IR, $\beta=0.11, p=0.02$. No significant effect of CRP was found in adjusted models (data not shown).

\section{Discussion}

Obesity is associated with whole-body insulin resistance yet this resistance may differ between insulin responsive tissues and not always be directly related to the degree of obesity. Moreover, altered glucose tolerance is typically associated with insulin resistance in adolescents with obesity and may be a confounder when studying the relation of the degree of obesity, subclinical inflammation, and adipose IR. Our findings indicate that the degree of obesity in childhood and adolescence is strongly associated, independent of glucose tolerance, with adipose tissue insulin resistance. This is reflected not only in calculated indices of adipose IR but also in lower suppression of FFAs during the OGTT in subjects with the 
highest degree of obesity, regardless of glucose tolerance or fasting adipose tissue IR. Furthermore, we show that markers of subclinical inflammation such as IL-6 are associated with adipose IR, independent of other factors and regardless of glucose-tolerance status. These observations demonstrate for the first time in adolescents with obesity that the degree of obesity is a crucial component in the development of adipose IR, possibly mediated by inflammatory cytokines derived from fat depots.

Adipose tissue is a key player in modulation of energy balance in general and glucose metabolism in particular. Glucose metabolism is regulated by the interplay of insulin secretion and insulin sensitivity. While insulin sensitivity is typically referred to insulin responsive organs such as the liver in the fasting state and skeletal muscle in the post-prandial state, adipose tissue tends to be less appreciated in this context. The regulation of FFA release from adipose tissue governs FFA plasma concentrations, which in turn affects both insulin sensitivity and secretion directly (reducing both after prolonged exposure) $[18,19]$. It has been shown that both FFAs concentrations and visceral fat are negatively associated with insulin secretion in obese adolescents [10]. Moreover, even overnight exposure to elevated FFAs administered exogenously has been shown to reduce both insulin sensitivity and indices of insulin secretion in obese adolescents [20,21]. Metabolites such as acetyl CoA, that are derived from inflamed white adipose tissue lipolysis, are the main regulators of gluconeogenesis and thus of hepatic glucose production [22]. Consistent with our studies, others have also shown the marked differences of adipose IR between obese adolescents with normal vs. impaired glucose tolerance $[4,23]$. In adults, the rise in adipose IR parallels that of beta-cell dysfunction in subjects with normal glucose tolerance prior to the development of overt diabetes [5]. These previous observations along with those presented herein suggest a role of lipotoxicity as a potential driver of altered glucose metabolism in pubertal adolescents.

Insulin resistance of the adipose tissue manifests mainly as reduced suppression of lipolysis and-to a lesser extent-in reduced glucose uptake [24]. Thus, understanding of adipose tissue IR independent of whole-body insulin sensitivity is of relevance to the understanding of glucose metabolism in obese youth. Our findings suggest that the resistance of adipose tissue to the effects of insulin is, indeed, directly associated with the degree of obesity, independent of glucose tolerance. This observation suggests that, above a certain amount of lipid storage, adipose tissue loses its capacity to continue the process of lipogenesis induced by ambient insulin concentrations at the same efficiency and rate that was present at lower amounts of adipose tissue mass. This is probably due to changes in cell size resulting in larger adipocytes, known to be less responsive to insulin and to be associated with altered glucose metabolism [25]. The reduced suppression of FFAs during the OGTT in those with greater degrees of obesity indicates that, above a certain adiposity threshold, both lower responsiveness to insulin resulting in nonsuppressed lipolysis and greater FFA release as well as reduced FFA clearance (not evaluated in this analysis) result in greater circulating FFA concentrations that create lipotoxic effects and alter glucose metabolism [26, 27].

In this analysis, concentrations of IL-6 were positively related with the indices of adipose tissue insulin resistance. Moreover, even after adjusting for age, sex, ethnicity, glucose tolerance, and the degree of obesity, IL-6 remained a significant predictor of prandial adipose IR. The present analysis adds another piece to the puzzle of the effects of adiposity in childhood, and shows that the concentration of markers of inflammation in obese children is linked to their degree of obesity and glucose tolerance as well as to their degree of adipose tissue insulin resistance. The development of dysregulated fat characterized by infiltration of immune cells such as macrophages [28] and inducing a pro-inflammatory hormonal profile may be an early driver of both insulin resistance and beta-cell dysfunction in obese adolescents [29]. This suggests that adipose derived cytokines such as IL-6 may have direct effects on insulin responsive tissues such as the liver and muscle, affecting insulin signal transduction pathways in them as well as on the effects of insulin in the adipose tissue itself [30]. Thus, the interplay of total body fat on one hand and fat distribution on the other contributes to the overall metabolic phenotype of children with obesity via the effects of intracellular lipid transport/deposition and via pro-inflammatory cytokines respectively. Moreover, these observations highlight the potential mechanistic role of subclinical inflammation, independent of the degree of obesity and glucose tolerance, with insulin responsiveness of adipose tissue, and may shed light on the pathophysiology of dysmetabolism in the context of the other chronic inflammatory diseases in this age group.

In the present analysis, we used a large sample size and investigated a broad spectrum of degrees of obesity which allowed us to shed light on the relations of the degree of obesity and the metabolic function of adipose tissue in obese children. Our observations need further validation using tracing of FFAs and evaluation of their turnover in the face of changing insulin concentrations as well as in children with similar degrees of obesity yet different lipid partitioning patterns. Whether the sensitivity of subcutaneous compared to intra-abdominal fat to insulin in these children is different needs further investigation as well. There are some observations in the literature that a significant weight loss may improve adipose IR [9], yet the flexibility of the metabolic characteristics of adipose tissue in the face of weight changes (both gain and loss) and whether adipose IR may be modified without weight changes (such as by the use of 
thiazoladinediones [31]) in this population need further investigation.

Funding This work was supported by the National Institutes of Health (NIH) (Grants R01-HD-40787; R01-HD-28016) and ADA Distinguished Clinical Scientist Awards from the American Diabetes Association (DK-49230) (S. C.). This work was also made possible by the CTSA Grant no. UL1 RR024139 from the National Center for Advancing Translational Science and by DK045735 to the Yale Diabetes Endocrinology Research Center, a component of the NIH, and NIH roadmap for Medical Research.

\section{Compliance with ethical standards}

Conflict of interest There is no conflict of interest that could be perceived as prejudicing the impartiality of the research reported.

Ethical approval All procedures performed in studies involving human participants were in accordance with the ethical standards of the institutional and/or national research committee and with the 1964 Helsinki declaration and its later amendments or comparable ethical standards. The study was ethically approved by the Human Investigations Committee of the Yale School of Medicine.

Informed consent Informed consent was obtained from all individual participants included in the study.

OpenAccess This article is distributed under the terms of the Creative Commons Attribution 4.0 International License (http://creativeco mmons.org/licenses/by/4.0/), which permits unrestricted use, distribution, and reproduction in any medium, provided you give appropriate credit to the original author(s) and the source, provide a link to the Creative Commons license, and indicate if changes were made.

\section{References}

1. Petersen MC, Shulman GI (2018) Mechanisms of insulin action and insulin resistance. Physiol Rev 98(4):2133-2223. https://doi. org/10.1152/physrev.00063.2017

2. Weiss R, Dziura J, Burgert TS et al (2004) Obesity and the metabolic syndrome in children and adolescents. N Engl J Med 350(23):2362-2374. https://doi.org/10.1056/NEJMoa031049

3. Luo L, Liu M (2016) Adipose tissue in control of metabolism. J Endocrinol 231(3):R77-R99. https://doi.org/10.1530/ JOE-16-0211

4. Hershkop K, Besor O, Santoro N, Pierpont B, Caprio S, Weiss $\mathrm{R}$ (2016) Adipose insulin resistance in obese adolescents across the spectrum of glucose tolerance. J Clin Endocrinol Metab 101(6):2423-2431. https://doi.org/10.1210/jc.2016-1376

5. Gastaldelli A, Gaggini M, DeFronzo RA (2017) Role of adipose tissue insulin resistance in the natural history of type 2 diabetes: results from the san antonio metabolism study. Diabetes 66(4):815-822. https://doi.org/10.2337/db16-1167

6. Burns SF, Kelsey SF, Arslanian SA (2009) Effects of an intravenous lipid challenge and free fatty acid elevation on in vivo insulin sensitivity in African American versus Caucasian adolescents. Diabetes Care 32(2):355-360. https://doi.org/10.2337/dc08-1102
7. Roden M, Price TB, Perseghin G et al (1996) Mechanism of free fatty acid-induced insulin resistance in humans. J Clin InvestIG 97(12):2859-2865. https://doi.org/10.1172/JCI118742

8. Carpentier A, Mittelman SD, Bergman RN, Giacca A, Lewis GF (2000) Prolonged elevation of plasma free fatty acids impairs pancreatic beta-cell function in obese nondiabetic humans but not in individuals with type 2 diabetes. Diabetes 49(3):399-408

9. Reinehr T, Kiess W, Andler W (2005) Insulin sensitivity indices of glucose and free fatty acid metabolism in obese children and adolescents in relation to serum lipids. Metab Clin Exp 54(3):397402. https://doi.org/10.1016/j.metabol.2004.10.008

10. Toledo-Corral CM, Alderete TL, Richey J, Sequeira P, Goran MI, Weigensberg MJ (2015) Fasting, post-OGTT challenge, and nocturnal free fatty acids in prediabetic versus normal glucose tolerant overweight and obese Latino adolescents. Acta Diabetol 52(2):277-284. https://doi.org/10.1007/s00592-014-0634-7

11. Bai Y, Sun Q (2015) Macrophage recruitment in obese adipose tissue. Obes Rev 16(2):127-136. https://doi.org/10.1111/obr.12242

12. Zabarsky G, Beek C, Hagman E, Pierpont B, Caprio S, Weiss R (2018) Impact of severe obesity on cardiovascular risk factors in youth. J Pediatr 192:105-114. https://doi.org/10.1016/j.jpeds .2017.09.066

13. Hagman E, Danielsson P, Brandt L, Ekbom A, Marcus C (2016) Association between impaired fasting glycaemia in pediatric obesity and type 2 diabetes in young adulthood. Nutr Diabetes 6(8):e227. https://doi.org/10.1038/nutd.2016.34

14. Kuczmarski RJ, Ogden CL, Guo SS et al (2002) 2000 CDC growth charts for the United States: methods and development. Vital Health Stat 11(246):1-190

15. Taksali SE, Caprio S, Dziura J et al (2008) High visceral and low abdominal subcutaneous fat stores in the obese adolescent: a determinant of an adverse metabolic phenotype. Diabetes 57(2):367-371. https://doi.org/10.2337/db07-0932

16. Matsuda M, DeFronzo RA (1999) Insulin sensitivity indices obtained from oral glucose tolerance testing: comparison with the euglycemic insulin clamp. Diabetes Care 22(9):1462-1470

17. Groop LC, Bonadonna RC, DelPrato S et al (1989) Glucose and free fatty acid metabolism in non-insulin-dependent diabetes mellitus. Evidence for multiple sites of insulin resistance. J Clin Investig 84(1):205-213. https://doi.org/10.1172/JCI114142

18. Smith U, Kahn BB (2016) Adipose tissue regulates insulin sensitivity: role of adipogenesis, de novo lipogenesis and novel lipids. J Intern Med 280(5):465-475. https://doi.org/10.1111/ joim. 12540

19. Nolan CJ, Madiraju MS, Delghingaro-Augusto V, Peyot ML, Prentki M (2006) Fatty acid signaling in the beta-cell and insulin secretion. Diabetes 55(Suppl 2):S16-S23. https://doi.org/10.2337/ diabetes

20. Hughan KS, Bonadonna RC, Lee S, Michaliszyn SF, Arslanian SA (2013) beta-Cell lipotoxicity after an overnight intravenous lipid challenge and free fatty acid elevation in African American versus American white overweight/obese adolescents. J Clin Endocrinol Metab 98(5):2062-2069. https://doi.org/10.1210/jc.2012-3492

21. Michaliszyn SF, Bonadonna RC, Sjaarda LA, Lee S, Farchoukh L, Arslanian SA (2013) beta-Cell lipotoxicity in response to free fatty acid elevation in prepubertal youth: African American versus Caucasian contrast. Diabetes 62(8):2917-2922. https://doi. org/10.2337/db12-1664

22. Perry RJ, Camporez JG, Kursawe R et al (2015) Hepatic acetyl CoA links adipose tissue inflammation to hepatic insulin resistance and type 2 diabetes. Cell 160(4):745-758. https://doi. org/10.1016/j.cell.2015.01.012

23. Kim JY, Nasr A, Tfayli H, Bacha F, Michaliszyn SF, Arslanian S (2017) Increased lipolysis, diminished adipose tissue insulin sensitivity, and impaired beta-cell function relative to adipose tissue 
insulin sensitivity in obese youth with impaired glucose tolerance. Diabetes 66(12):3085-3090. https://doi.org/10.2337/db17-0551

24. Bódis K, Roden M (2018) Energy metabolism of white adipose tissue and insulin resistance in humans. Eur J Clin Investig. https ://doi.org/10.1111/eci.13017

25. McLaughlin T, Lamendola C, Coghlan N et al (2014) Subcutaneous adipose cell size and distribution: relationship to insulin resistance and body fat. Obesity (Silver Spring) 22(3):673-680. https://doi.org/10.1002/oby.20209

26. Stinkens R, Goossens GH, Jocken JW, Blaak EE (2015) Targeting fatty acid metabolism to improve glucose metabolism. Obes Rev 16(9):715-757. https://doi.org/10.1111/obr.12298

27. Saponaro C, Gaggini M, Carli F, Gastaldelli A (2015) The subtle balance between lipolysis and lipogenesis: a critical point in metabolic homeostasis. Nutrients 7(11):9453-9474. https://doi. org/10.3390/nu7115475

28. Shapiro H, Pecht T, Shaco-Levy R et al (2013) Adipose tissue foam cells are present in human obesity. J Clin Endocrinol Metab 98(3):1173-1181. https://doi.org/10.1210/jc.2012-2745
29. Caprio S, Perry R, Kursawe R (2017) Adolescent obesity and insulin resistance: roles of ectopic fat accumulation and adipose inflammation. Gastroenterology 152(7):1638-1646. https://doi. org/10.1053/j.gastro.2016.12.051

30. Mauer J, Chaurasia B, Goldau J et al (2014) Signaling by IL-6 promotes alternative activation of macrophages to limit endotoxemia and obesity-associated resistance to insulin. Nat Immunol 15(5):423-430. https://doi.org/10.1038/ni.2865

31. Gastaldelli A, Harrison SA, Belfort-Aguilar R et al (2009) Importance of changes in adipose tissue insulin resistance to histological response during thiazolidinedione treatment of patients with nonalcoholic steatohepatitis. Hepatology 50(4):1087-1093. https ://doi.org/10.1002/hep.23116

Publisher's Note Springer Nature remains neutral with regard to jurisdictional claims in published maps and institutional affiliations. 